\title{
Case Study of a Performance-active Changing Trans* Male Singing Voice
}

(final draft before published version)

\author{
Alexandros N. Constansis \\ Independent Scholar \\ York, UK. \\ changingvoice@gmail.com \\ Aglaia Foteinou \\ University of Wolverhampton \\ Wolverhampton, UK.
}

\begin{abstract}
A professional classical singer of more than 25 years (AZ) in his early fifties requested this voice researcher's consultation and assistance in early 2014 . He was about to start living full time as a trans* man. Despite his intention to be included in the low start/gradual increase testosterone option of the Trans* Male (previously, "FTM") Singing Voice Program, the request contained a rather unconventional aspect: $A Z$ would continue to sing while his voice was changing. The above request was integral with his singing history. After the introduction of safeguards and his informed consent, AZ was accepted onto the Program. Due to the highly individual circumstances, his participation was recorded as a case study.

The study has aimed to replicate the particulars of the slow hormonal changes and continuing singing ability found in certain cisgender male adolescent voices. Despite dealing with an adult trans* male individual, the progress has been comparable. This has been achieved by carefully monitoring AZ's low start/gradual increase testosterone administration in communication with the medical practitioner. The participant's vocal health remained safeguarded and promoted by carefully individualized vocal tuition. This article will discuss the collective results of the case study, including the recordings and the data analysis.
\end{abstract}

Keywords: Performance-active; Changing Singing Voice; Trans* Male; "Female"-toMale ("FTM"); Singing Vocality; Voice Data Analysis. 


\section{Introduction}

Whereas adept music-instrument playing is an extension of the musician's persona, a human voice is always personal. Apart from observing certain common technical aspects, such as good diaphragmatic breathing and appoggio ${ }^{1}$, a fully-developed voice frequently creates and imposes its own rules. Rules which the singer as well as the coach/practitioner should be able to observe judiciously. Irrespective of such concerns, a mature vocal expression, speaking and/or singing, should be as distinctive as someone's fingerprints. There are cases, however, when vocal personae, such as those of trans* men and trans* women, are encouraged to develop not independently but by replicating certain gender-specific standards of pitch and expression (e.g. Carew et al. 2007). The results of such vocal imitations are a priori restrictive and less than ideal. Nevertheless, they are being promoted as means to protect from the effects of societal pressure and harassment and, thus, are still widely accepted. Due to the emphasis on speech, even when approaches, such as MIT (Melodic Intonation Therapy) are used (e.g. Hershberger-Georgiadou 2005), the consequences of such imitation are less prominent in the field of trans* singing vocality.

The effects of any vocal change usually make the average professional singer uneasy. In the case of a female-to-male or trans* male professional singer who transitions, however, there is truly too much at stake. Apart from surviving a stressful gender transition, such a life-changing decision is accompanied by immediate concerns about the survival of someone's singing vocality. If, therefore, either the person or the voice practitioner is not careful enough, then the results can prove unpredictable - even catastrophical - for the transitioning singer. According to Gorton et al., "professional or amateur singers and speakers should be warned that frequently voice changes occur that may be significantly detrimental to vocal performance." $(2005,59)$ This is what has been described in my work as "entrapped" trans* male (or FTM) vocality. ${ }^{2}$ Such concerns became immediately obvious when, in early 2014, the case participant (AZ), a fifty-one-year-old professional singer residing in the general geographical area of Southern California, USA, requested my consultation and guidance.

\section{The Case Particulars}

The communication with AZ, mostly via email and on Skype, started in late 2013. As part of that online interaction, the prospective participant received several informative and scientific documents discussing the characteristics of changing singing vocality as well as the various parameters and options associated with the female-to-male one.

The specifics were rather unusual: the singer needed to transition in such a way that would safeguard his continuing singing ability throughout the various stages of his voice changing process. Such an ability is, theoretically and practically, known to be feasible in other types of changing vocality. For instance, the "boy soprano drops

\footnotetext{
${ }^{1}$ The importance of diaphragmatic breathing, and appoggio techniques is paramount for this group of singing voices. This is because the above techniques are among the primary factors which can counteract the effects of the lesser development of the trans* male physical body and voice instrument. Thus, they can ensure a healthy, full of harmonics, and resonant vocal delivery, without the use of amplification.

2 The details about the "entrapped FTM Voice" and the recommended methods to prevent it have been included in my doctoral thesis (Constansis 2009, 254ff) and "The Changing Female-to-Male (FTM) Voice" article (Constansis 2008, pars.4ff).
} 
to a boy alto, then into what could well be called a countertenor $\left(F-f^{1}\right)$, then into the standard tenor, always keeping the range intact. These youths are easy to work with; as they drop slowly, they seldom develop any passaggio problems" (Swanson 1981, 34). Although the aspect had been noted in the male adolescent voice, it had not yet been exhaustively tested in a fully-active female-to-male professional singer. The above specific made me keen as well as apprehensive at the same time. While my researcher's perspective recognized the potential, my singing practitioner's commitment to safe singing became challenged.

As discussed, despite my significant face-to-face (since 1990) as well as online teaching experience (since 2006), the participant's request contained, from the start, uncharted territory. This was not only intensified by the well-noted limitations of the e-learning process (see Price et al. 2007) but also the sheer geographical distance (my vocal practice is in the UK). Bearing in mind that face-to-face tuition was never an option, thorough planning was the only means to control the research and practice conditions. In spite of the uncharted territory as well as distance, the case study produced reliable and, based on a similar singing background, replicable results. Before we proceed, let us briefly discuss the reasons behind the terminological change and then compare the case study results with those of the main Singing Trans* Male ("FTM") Voice program, which, since its introduction in June 2004, remains independent and without official funding.

\section{From "Female-to-Male" to Trans* Male: A Terminological Transition}

The primary work on the singing "Female-to-Male" or trans* male voice and vocality started in the summer of 2002. In the early 2000s, as demonstrated by most relevant literature (see Van Borsel et al 2000; Van Borsel et al 2001), the terms "Female-toMale (FTM)" and "Male-to-Female (MTF)" transsexuals were not only considered to be current but almost cutting edge. ${ }^{3}$ Genderqueer options were still rarely discussed or even contemplated. Thus, the "FTM" and "MTF" acronyms were widely used by most masculine or feminine-identified trans people in the UK. In the same chronological context, the term "transsexual" was also preferred by UK people who wanted to transition through means of hormonal and primary/secondary anatomical changes. The purpose of the above gender-affirmation process is to allow individuals to live full-time as themselves, that is, in their true gender. The term "transgender", an umbrella term currently used almost worldwide, was still rarely employed in Britain by those pursuing a gender-affirmation process (for the distinction between the two terms and its associated history, see Whittle 2006; Shepherdson 2006; also, Stryker 2008, 18-19).

The fifteen intervening years have brought cosmogonic changes in $\mathrm{UK}^{5}$ and international law ${ }^{6}$, and, thus, in the everyday lives of trans people, mostly, in western societies. These legal and social changes have been the result of developments in gender/queer and, most directly, transgender theory and studies (see Stryker 2008 \&

\footnotetext{
${ }^{3}$ In the eighties and nineties, trans* male ("female-to-male") and trans* female ("male-to-female") individuals used to be mostly defined by their biology. Thus, the most common way for them to be referred to was, in respect, as female and male transsexuals (e.g, Verschoor and Poortinga 1988). Such outdated and insensitive use of terminology, although rare, is still applied by certain medical teams (see EPATH Program 2017, 28).

${ }^{4}$ The above acronyms are also frequently presented as FtM and MtF.

${ }^{5}$ For instance, the Gender Recognition Act [GRA] 2004.

${ }^{6}$ On April 12015 the Maltese Government adopted the Gender Identity, Gender Expression and Sex Characteristics Act (GIGESC Bill). Transgender Europe welcomed the Bill as "a historic break-through for the rights of trans and intersex people in Malta and Europe." (TGEU 2015, online).
} 
2006). Nowhere else is this reflected more clearly than in the updated and upgraded use of terminology. In a relatively short time, terms that used to be current or, even, cutting edge have now become practically obsolete. Since the full range of trans or, more inclusively, trans ${ }^{*}$ identities a priori supersede people's biological traits, quasi biologically-based and descriptive references, such as "female-to-male" and "maleto-female", seem to be the ones affected the most. In 2017, there is an increasing number of trans* individuals who treat them as painful reminders and/or insults to their true identities. Both reasons more than justify a transition to trans ${ }^{*}$-friendlier terms, such as the all-encompassing trans with an asterisk (trans*), which has also become this author's preferred term since 2015. Trans ${ }^{*}$, as defined by Global Action for Trans* Equality (GATE 2015), describes

those people who transgress (binary) (western) gender norms, many of whom face human rights issues as a result. (...) The term trans ${ }^{*}$ should be seen as a placeholder for many identities, most of which are specific to local cultures and times in history, describing people who broaden and expand a binary understanding of gender.

Apart from an in-depth understanding of issues related with gender, a queer musicologist's role is to respect, reflect and, frequently, reconstruct the music past. As part of it, scholars need to know both current and original eras in depth. This would allow them to differentiate and, thus, prevent the mirroring of ideas from the former to the latter. In the twenty-first century, the eras not only change faster than before but can truly become superseded within decades rather than centuries. This factor makes current research matters increasingly complicated. We can see that in the case of non-binary trans* and gender-queer singers, who have become normative in 2017. However, in 2008, singing and non-singing individuals in the UK had to hide their true identities or risk the failure of being accepted by Gender Identity Clinics. This demonstrates why, despite the close proximity, transferring or imposing standards from one decade to another and/or from one location to the rest of the world would be scientifically risky.

Contrary to that of a musicologist, a singing practitioner's function is to work with the present, even when studying and performing the past. Therefore, today's singer's general and voice health must always take precedence over yesterday's ideas and practices. Consequently, current perceptions about artistic health and integrity would not allow abusive interventions, such as the infamous castratio euphonica $^{7}$, to take place and, thus, produce this kind of artistic perfection. For similar reasons but without a thorough reasoning, such accusations can be brought against trans* singers by conservative and frequently inadequately informed scholars. It is rather surprising that the same background mostly ignores the continuing abuses against underage intersex individuals. The above reductio ad absurdum $^{8}$ demonstrate the limitations in twenty-first century concepts of primum

\footnotetext{
${ }^{7}$ Castratio euphonica or euphonic castration, within a Roman Catholic context, mostly took place from the mid- $16^{\text {th }}$ to the late $19^{\text {th }}$ centuries in Italy and other European countries. As stated by Feldman, during the above period "many boys were castrated to be made into full-throated adult sopranos" (2015, xi). The creation of such beautiful, quasi-angelic, high male voices fulfilled another important role: to "keep females away from liturgic services" (Wille and Beier 1989, 107). Ecclesiastically, however, the justification for the presence of castrati voices in churches was to serve the Glory of God on earth, known as Ad Honorem Dei (for references and examples on both castration and the quasidogma of Ad Honorem Dei, see Constansis 2009).

${ }^{8}$ That is, logically fallacious.
} 
non nocere ${ }^{9}$. They also reveal the need for a singing researcher and queer musicologist to be perfectly balancing on both sides of scholarly inquiry.

\section{The Singing Trans* Male ("FTM") Voice Program vs. the AZ Case Study: Similarities and Differences}

From March 2003 to March 2004, the parameters of the Singing FTM Voice project, later Program, were first tested by myself in the dual capacity of researcher-first participant. Soon after (June 2004), external participants, with a minimum of one year's previous singing experience, started joining the scheme. On September 2004, "The Changing FTM Voice" paper discussed the first results of the study (Constansis, in $6^{\text {th }}$ International Congress on Sex and Gender Diversity), which initially focused on my dual experiences as the first participant and researcher/practitioner. As part of the research project, I tested the efficacy of several classical and modern singing techniques and produced a series of recommended exercises (see Constansis 2008, par. 21-23). Primarily though, based on my previous singing and tutoring background, I advocated a different than usual hormonal regime, i.e. a low start/gradual increase (2008, par. 16-20). On the contrary, the majority of participants joining from 2004 and until 2007 continued to follow the then widely accepted method of abrupt/injectable testosterone administration, i.e. Sustanon $250 \mathrm{mg}$, bimonthly. Despite them being, initially, the larger sample population, those participants who followed the abrupt method eventually became the control group of the study. Until early 2009, the low start/gradual increase method of testosterone administration was still treated with suspicion, not only by medical professionals but also by female-to-male (FTM) trans* people. As stated by Levy et al., "doubts about the integrity of transgender individuals and the authenticity of gender dysphoria as a diagnosis [had led] some members of the medical profession to withhold treatment or prescribe inadequate doses of cross-sex hormones on safety grounds" $(2005,416)$. Irrespective of participants' choosing the low start/gradual increase or the abrupt method of testosterone administration, they all followed the same exercising regime and committed to a minimum of "one year's involvement" (Constansis 2008, par. 24; see also par. 25).

Like all previous participants, AZ received detailed information about the program before consenting to participate for one year (low start/gradual increase section). Due to the richness of his professional singing experience, however, as well as the importance for him to retain his singing ability throughout his transition, the mode of hormonal administration had to take a slower pace than usual. This was dictated by his voice and its progress. In principle, every increase in the hormonal administration regime was followed by a six-week, on average, period of stabilisation ${ }^{10}$. During the second part of his one-year participation, the above was

\footnotetext{
${ }^{9}$ In full, primum non plus nocere quam succurrere means "above all, do not harm more than succour". Although the dictum, in its shortened form (see main text), is translated as "first do no harm", it should be, more accurately, expressed as "first do no net harm". According to Sokol, the above implies that, at "an individual level, physicians must balance their obligation to benefit the patient (the principle of beneficence) against their obligation not to cause harm (the principle of non-maleficence). These twin obligations go hand in hand and are weighed against each other." (2013, 347, f2426).

${ }_{10}$ Methods of gel testosterone administration involving metered-dose pumps can prove particularly helpful for singing trans* men choosing the low start/gradual increase hormonal regime. Singing participants in the Trans* Male Singing Voice Program start from the lowest feasible dose. Then, at regular intervals (i.e., every four weeks for the Program and six for the Case Study), the level is titrated upwards until an optimal dosage is reached. Although there is a recommended dosage, this
} 
accompanied by an additional and carefully devised set of exercises. For all the above factors, AZ's participation had to be treated as an individual case study. Irrespective of special characteristics, similarly to the Program participants, the case study was carefully constructed bearing in mind issues of health and safety as well as anonymization and safeguarding applicable to sensitive groups and, especially, trans* people. As part of the above, the participant had the terms of his participation explained in detail before the obtaining of his written consent. Throughout his participation, AZ was carefully instructed on vocal hygiene and safe and effective singing technique for each stage of his vocal development. He was also coached on suitable repertoire and effective delivery. His participation was also safeguarded by a thorough anonymization process, e.g. the various aspects of the active case study were recorded under a pseudonym, chosen by him, whilst his personal details and any original records were never transcribed electronically but kept as hard copies. The folder which contained them was stored into a safe and remained inaccessible to anyone but myself. The above documentation was safely destroyed on September 30 2015, i.e. one and a half years from the official start of AZ's participation. In general, anonymization for participants who belong to sensitive groups would require additional care and safeguarding, especially, when the above individuals and/or their social circle are actively involved in social media.

\section{Anonymization in the Age of Social Media}

Similarly to all studies involving human participation, participants of the Singing Trans* Male ("FTM") Voice Program are entitled to a full and genuine anonymization process. When the above principle is thoroughly observed and respected, participants' personal details cannot be identified by anyone else apart from themselves. However, the task of fully anonymizing trans* participants' details is not an easy one. It requires not only careful thinking by the researcher and/or practitioner but also consideration and in-depth understanding of the particulars associated with the protection of trans* lives. For instance, whereas the details of a cisgender ${ }^{11}$ tenor singing in a choir can be successfully anonymized by using his age and location, in the case of a trans* singer the same details may be sufficient to unwittingly expose a participant, frequently the only one of his age and living in such a location. The above demonstrates how certain researchers' and/or UK National

should ideally be decided by the endocrinologist based on each trans* man's general health and serum testosterone levels. Moreover, unless there are health or other related issues, trans* male singers on the low start/gradual increase method of hormonal administration should continue using the same type of gel medication throughout their transition. Variant types of testosterone in gel format, even those administered through metered-dose pumps, are frequently incompatible and incomparable. Following the same type and form of gel medication is currently the approach that produces the most reliable low start/gradual increase administration results.

${ }^{11}$ As mentioned by Aultman,

The term cisgender (from the Latin cis-, meaning 'on the same side as') can be used to describe individuals who possess, from birth and into adulthood, the male or female reproductive organs (sex) typical of the social category of man or woman (gender) to which that individual was assigned at birth. Hence a cisgender person's gender is on the same side as their birth-assigned sex, in contrast to which a transgender person's gender is on the other side (trans-) of their birth-assigned sex.

Cisgender emerged from trans* activist discourses in the 1990s that criticized many commonplace ways of describing sex and gender (2014, 61-62). 
Health Service (NHS) specialists' partial awareness of individual circumstances about the trans* condition or, even, hidden transphobia (see Women and Equalities' Committee Report 2015) can result in only partial anonymization or "pseudonymization". Partial pseudonymization on the NHS, as described by Brown et al. is "a euphemism to describe measures which perhaps prevent immediate identification of individual patients by the person using the data, but which do not make re-identification impossible or even difficult--indeed, which are specifically aimed at keeping data that will open up the possibility of re-identification of patients" (2010, in Brown et al. 2011). In cases of inadequate attention to scientific rigor when dealing with gender-variant participants, the above partial anonymization process can easily result in the outing and/or even endangerment of their lives.

In the Singing Trans* Male ("FTM") Voice Program, anonymization is achieved by a variety of methods, such as the use of codenames, which, unless they happen to coincide, they remain the participants' choice. Following that, the researcher ensures the careful disassociation of any results, for instance audio samples, obtained throughout each participation, and personal details, which are always kept in a different location, under lock and key and for a strictly specified period of time. In principle, the above time is defined as one and a half year from the beginning of each one-year participation. This can only be extended in cases of extraordinary circumstances and after a mutually agreed and signed amendment of the original participation consent form. The beginning of each participation circle is established through the signing dates contained in the original consent form/s.

Apart from the already established issues in anonymization process, participants can also unwittingly jeopardize themselves; especially in this era of social media. For example, singing individuals, despite researchers or practitioners' recommendations, may discuss their progress through social media platforms, such as Twitter of Facebook. Thus, twenty-first century research professionals need to treat such a possibility as a near certainty when anonymising participants' data. Among the various available methods, a researcher can address such a problem by avoiding the use of full geographical parameters. For instance, instead of naming participants' cities in publications, it is better for the researcher to mention general areas, e.g. Southern California or North Yorkshire. When the nature of the published data is, however, expected to be more identifiable, e.g. social graphs, methods, such as k-anonymization, should be applied (Rossi et al. 2015). Due to the variability in residents' attitudes as well as individual circumstances, anonymization process must not be relaxed as a result of positive or negative local attitudes towards trans* people.

\section{AZ: Case Particulars}

Despite the presence of analogous examples in the adolescent male voice (e.g. Swanson 1981, 34), the principle of continuing singing ability had only been partially tested in the transitioning female-to-male vocality. For instance, in the capacity of the first participant of the Singing FTM Voice Program, I retained an uninterrupted singing ability until nine months into my transition. Despite my following of the low start and gradual increase method of testosterone administration and a carefully devised exercising regime (both described in Constansis 2008), I experienced a voice break soon after the introduction of $100 \mathrm{mg}$ testosterone injections (see 2008, pars. 17-18). Unlike in recent years, testosterone injections, in the form of Sustanon 100 and $250 \mathrm{mg}$, were only administered bimonthly. Especially the potency of $250 \mathrm{mg}$, instead of facilitating the retention of singing ability during transition, has the 
increased potential to cause "entrapped" vocality (see Constansis 2009, 259-261). That is why, this form of testosterone administration should be chosen by singers only when a trans* man's vocal transition has been completed. Even then, gel forms, such as Testogel and Tostran, have been demonstrated to be kinder to the singing voice (see Constansis 2009 and 2013). Depending on biological parameters as well as the individuals' careful observance of optimized methods of application, gel forms can produce good absorption rates, almost in par with injectable and more concentrated forms of testosterone. Due to the limited evidence, however, the absorption rates of different forms of testosterone administration is a field which would benefit from further independent investigation.

\section{Other Advantages and Challenges}

A lengthy professional singing career, such as that of $A Z$, presents the voice researcher and practitioner with positive as well as negative elements. For instance, participants with previous experience and knowledge of the voice mechanism are frequently reluctant to change an established singing regime; even when their changing and/or hybrid singing instrument (see Constansis 2009) requires a drastically different approach. It takes time as well as careful negotiation skills for the practitioner to convince experienced singers that it is to their interest to leave their previous knowledge aside until their changing voice settles in its new tessitura. Despite the practitioner's talents, however, a professional singer will always perceive a new singing regime as an unnerving experience (see Moriarty 2015; Vest 2014; Hickey 2011). Apart from the effects of habit, feelings of doubt and emotive reactions can frequently hinder the sense of positive achievement. The above can be aggravated by the presence of coexisting conditions.

$A Z$ is affected by an attention deficit condition or ADD. The participant's use of older terminology is based on the third edition of the North American Diagnostic Statistical Manual (DSM-III, 1980, American Psychiatric Association). In 1994, the condition was renamed Attention Deficit Hyperactivity Disorder or ADHD (for more details, see Timimi and Leo 2009). As stated by Biederman, the aetiology behind the condition "has not been clearly identified, although evidence supports neurobiologic and genetic origins" (2005, 1215; for more on the Cause of ADHD, see Biederman and Faraone 2005). As a result of the above, the participant exhibited mild and very idiosyncratic additional learning support issues. Although the above may have affected the participant's knowledge acquisition in areas, such as music theory, such issues never impended his singing progress, for instance, when learning new music scores. This is far from an unknown characteristic of talented singers, albeit those mostly from an older generation and with a strong background in practical rather than theoretical musicianship, such as Luciano Pavarotti or Enrico Caruso who "also had rudimentary knowledge in music theory" (see Tommasini 2007, online).

Attention deficit conditions are frequently accompanied by a lesser inability to concentrate and, thus, negotiate certain concepts. As a result, individuals with ADHD may also compensate in an attempt to avoid detection (see Roberts, Milich and Barkley, in Barkley 2014). In this specific case, both above issues became increasingly prominent, especially when vocal changes started becoming more noticeable. Moreover, as stated by Roberts, Milich and Barkley, individuals with ADHD often "make decisions impulsively" (2014, 57) and against warnings or recommendations. Because of the above frequent occurrences, I had to view the participant's case not only through the lenses of my experience with charismatic singers but also with those with additional educational needs (I first became a music 
tutor in the field of variant learning abilities in 1990). Although the occurrence of ADD/ADHD in singers has not been adequately studied, it is far from unknown (see Melago 2014; Swanson 2007).

\section{Face-to-face Meetings: Beginning and End of Participation}

Even though the communication with $A Z$ started online, the prospective participant had already planned his UK visit in late February/early March 2014. In the meantime, as part of our frequent communication, $A Z$ had received a number of informative and scientific documents discussing the characteristics of changing vocality and, particularly, the singing trans* male one. Some of them also discussed the possibility of retaining singing ability throughout the physical and vocal changes. After discussing the various options, I explained why, based on current research and practice, a continuing singing ability in a trans* male transition may only be supported by a carefully-adapted low start/gradual increase method of testosterone administration, preferably by gel. Although the prospective participant agreed, I was concerned because he still demonstrated inadequate understanding of the effects of testosterone administration. As such, I requested for him to wait for our imminent face-to-face meeting in the UK, in less than ten days, before committing to participate. Due to the above, I needed to explain all above issues to him thoroughly and in person.

Our UK meeting revealed that, in spite of my request, the prospective participant had already started his hormonal administration. Moreover, his endocrinologist had prescribed a standard (i.e. abrupt, method of injectable hormonal administration). Thus, AZ's physical appearance and voice had already started demonstrating some initial signs of changing. Given his history of rosacea and its possible health implications, including the masking of other conditions (see Talley and O' Connor 2014, 170; Norman 2008, 81), I became worried by the particularly dark red color of his face. I sensitively brought the above concerns to his attention. Moreover, after checking and confirming - through a photograph - the type and dosage of his injectable testosterone, I asked the prospective participant, once again, to confirm his intention to maximize the potential for retaining his singing ability throughout his transition. When AZ confirmed such a commitment to me, without worrying him too much, I tried to explain the known consequences to him. He still did not realize the extent of the changes that were about to follow. I asked him to get in touch with his endocrinologist and discuss the reasons why his specific request for a low start/gradual increase testosterone administration had been ignored.

Within one week the prospective participant's head range started exhibiting a "harsh metallic" quality signifying, particularly in trans* men, an imminent and significant voice change. I immediately underlined that, as long as AZ was happy with the near certainty of his voice's "breaking" and, thus, his immediate inability to participate in any further professional singing activities, I would include him in the Program, within the control group, i.e. the one following the abrupt method of testosterone administration, and support him in his choice. Such a prospect made the participant extremely unhappy though. He, once again, reiterated his wish to retain his singing ability throughout his transition. Seriously doubting the outcome, I recommended his immediate meeting with his previous or a new and more specialized endocrinologist. In the meantime, to reverse any unwanted changes, $A Z$ was advised to cease any further hormonal intake for one month. In addition, AZ had to drink 2 litres of water daily. Very soon the prospective participant was able to 
find more specialized medical support. This allowed him to commence his new gelbased low start/gradual increase testosterone regime and his participation in this Case Study, after submitting his consent form.

\section{The Participant's Previous Voice Type and Performing Profile}

The singer, originally from the UK, had the opportunity to study singing on both sides of the Atlantic. For a variety of reasons and in spite of receiving a scholarship, AZ did not graduate in his music studies from either of the two major institutions. He had, however, already obtained an ABRSM Grade 8 in Singing. ${ }^{12}$ The lack of university qualification in singing never prevented him from pursuing a very active career. For twenty-five years, AZ was considered to be a truly gifted performer within his field. As a result, he "was employed as a professional member" (2015, personal communication) in an A House opera company as well as smaller opera groups in the USA. The singer got his first agent in 1995 and his active performing profile "became even more active and remained so until 2014" (2015, personal communication); the year of his official female-to-male transition. His opera roles included Cherubino and Sextus (from Le Nozze di Figaro and La Clemenza di Tito by W.A. Mozart), Ruggiero and Xerxes (from Alcina and Xerxes by G.F. Handel), Stefano (Romeo and Juliet), Prince Orlofsky (Der Fledermaus by Johan Strauss) as well as "tons of concert repertoire" (2015, email). Officially, AZ's previous voice fach was that of a mezzo soprano/alto. Due to its extensive range of more than three octaves as well as the ability to perform dramatically different repertoires, however, the voice type should be more accurately described as that of a soprano sfogato or assoluto/a. This term, frequently translated into English as "vented" soprano, can be considered a misnomer. This is because it truly defines a contralto voice which, due to careful and knowledgeable coaching, specialist exercising and sheer talent, manages to extend the upper tessitura to such a degree that it encompasses the coloratura soprano range. The sfogato or assoluto, nowadays a rarely recognized and, thus, highly-debated vocal category, remained, until the end of the nineteenth century, largely associated with a few "sacred monsters" in the history of the art of singing (for more information on the currently debatable nature of the sfogato voice, see Snider 2012; for $19^{\text {th }}$ century attitudes, see Lamperti 1939 [orig. 1841]). Among them, we can find female singers, such as Maria Malibràn (nineteenth century) and Maria Callas (twentieth century), and male castrati singers, such as Farinelli (eighteenth century). In all such cases, the singers, similarly to $A Z$, possessed an uncharacteristically low range for someone singing soprano roles.

Although, throughout my career, I have had the opportunity to experience talented singers who sometimes relied on their exceptional gift and did not feel the need to practice their breathing and appoggio exercising techniques as regularly as less gifted ones, the above approach is rarely beneficial to the vocal instrument in the longer term. Even without the extreme demands of a vocal transition, in this case from "female" to male, a voice tends to age and lose its accuracy faster if not exercised carefully and consistently throughout its active life. The importance of the above is underlined by voice teachers and coaches as well as medical voice specialists. Sataloff et al. characteristically state that voice "exercise is as essential

\footnotetext{
${ }^{12}$ Although the Associated Board of Royal Schools of Music (ABRSM) is British in origin, the exams and qualifications, which bear the same requirements, can be obtained worldwide. The following link provides the rules and repertoire required for Grade 8 singing exams (USA): http://us.abrsm.org/en/our-exams/singing-exams/singing-grade-8/ .Accessed: May 152017.
} 
to the vocalist as exercise and conditioning of other muscle systems is to the athlete." (2007, 938) Despite AZ's singing beautifully in his previous extensive range or repertoire, the effects of middle-age in combination with an inadequate application of appoggio had started to create issues, such as the presence of a "wide vibrato". The singer was still performing as an opera soloist as well as being one of the main singers in highly acclaimed professional choirs. Despite his official later-in-life transition, the singer's progress was not going to be interrupted by surgeries. This is because AZ knew his true gender identity from an early age. He only delayed his gender affirmation due to his singing career. This is demonstrated by the fact that he had had completed his mastectomy in 2001 and his hysterectomy - albeit, for singing purposes, without removing the ovaries - almost ten years before the beginning of March 2014. In spite of this, his vocal transition was anticipated to be a delicate one.

When I first heard the singer's voice (February 2014, UK), I appreciated an accomplished performance characterized by a wide range, strong volume, expressivity and stylistic knowledge as well as rich harmonics. Nevertheless, the strong singing demonstration was diminished by the use of a rather "wide" vibrato (see Sundberg 1994; Howes et al. 2004). Although this is frequently a characteristic of operatic soloists and choristers, it is also a distinguishing quality of aging and, particularly, menopausal singers (see Sataloff and Linville, in Sataloff 2006, 74). This was supported by the singer's concurrent experiencing of "hot flushes". According to $A Z$, this was the reason behind the endocrinologist's advice for an immediate start on testosterone. Nevertheless, based on the singer's initial interview, the medical doctor either misunderstood or ignored the participant's intentions. Moreover, the specialist failed to fully explain the injectable method's outcomes to the singer so that he could form a proper opinion. Although as a researcher I also bore the possibility of the singer's misunderstanding in mind, this assumption was never confirmed. Irrespective of the cause, the outcome for the singer was positive: it allowed him to find a more considerate medical practice.

As already stated, unlike the absolute majority of participants on the Singing Trans* Male (pr. FTM) Voice Program, even those on the low start/gradual increase group of testosterone administration, AZ needed to continue performing for as long as possible. This required slower progress than other participants in the low start/gradual increase group in terms of hormonal administration and longer and uninterrupted periods of stabilisation on his developing new technique. In the Singing Trans* Male Voice Program, the usual method for the group following the low start/gradual increase method of administration involves the practitioner making sure that any changes are incorporated for around three to four weeks before an increase in the individual hormonal regime can be recommended and negotiated. As already stated, in AZ's case this needed to be even longer as well as being accompanied by a more inventive than usual series of exercises (an example of the typical exercises for the Singing Trans* Male ("FTM") Voice Program can be found in Appendix 1), which had to change in order to help his voice change safely. Among these exercises, which we will have the opportunity to discuss in the relevant section, I should name the extensive application of sirens or glissandi and that of unvoiced liptrills followed by open-voiced exercises. Both of these proved particularly useful in the singer's case. This type of individualized hormonal and exercising regime allowed AZ to continue performing professionally until nearly the end of 2014 . Towards the end of that period he also took part in an audition in his new vocal range as a hybrid tenor-baritone (see Constansis 2009). Despite only being 
accepted as an extra singer, his audition was praised by the choir director and his colleagues alike. Nevertheless, the choir director clearly stated that, as well as underlying concerns about the singer's range and his health and safety as a result of the demanding repertoire, meant that they could only accept $A Z$ as an extra professional chorister until his voice was fully settled. Reading between the lines, this also meant that they were waiting until a more cisgender male comparable singing range and timbre had been acquired. ${ }^{13}$

The singer's range around the time of the above audition was from B flat $(b)$, not very audible, up to $F$ sharp (\#), frequently unstable. At the time of the completion of his participation, the singer's wide vibrato had almost been eliminated and his tonal quality was pure and stable. In the mid to lower areas of his range, however, the singer's developing voice instrument still presented some inconsistencies. However, these were easily avoided or corrected when, before a specific exercise or phrase section, he was asked to perform an unvoiced lip trill. The singer's range in March 2015 was almost two octaves, from low G (still rather weak) to A flat (b). These were regularly achieved but only as part of each lesson's concluding exercise. Moreover, the voice at the lower end of the range was still negotiating the technical changes necessary to stabilize in the new tessitura. Although not currently singing at a high professional level, $A Z$ is still singing in a small semi-professional choir. The singer completed his participation in this Case Study in early March 2015 (UK). His final performance of Handel's "Where'er you walk" (from Semele) is discussed below. ${ }^{14}$

\section{Final Recordings: March 2, 2015}

As demonstrated in the recordings (see the following Acoustic Analysis by Aglaia Foteinou, Ph.D.), the singer's performance on March 2, 2015, which was recorded in a York-based studio practice room and with an iPhone 5, was characterized by wide range, professional phrasing and in-depth stylistic knowledge. Moreover, in terms of acoustics, it is characterized by rich harmonics as well as a singer's formant. Despite the truly high level of his vocal performance, which was also not affected by his pretransitional wide vibrato, the singer was nervous (see the false start described in the audio analysis section) and could not fully appreciate his performance; a viewpoint never shared by his vocal coaches, fellow colleagues or other impartial listeners. Nevertheless, AZ has never learned to appreciate his recorded performance. Based on the singer claims, he has always had a problem with his recorded singing voice. This is far from unknown among classical singers; especially, those of an older generation. Gates et al., however, explain why singers hear their voice differently as a result of their audio-oral physiology $(2013,201)$. Another important factor is that the average classical singer records his/her voice far less frequently than the typical popular genre vocalist. Such rarity makes the former group of singers underappreciative of their recorded performances. The problem can only be counteracted by more frequent recordings and listening of the voices as part of a continuing learning process.

\footnotetext{
${ }^{13}$ Mainstream choir directors have studied and, thus, become accustomed to a specific type of classical singing voice, volume and timbre. Therefore, anything which supposedly deviates from the above sound and does not meet their well-established criteria and preferences (or, depending on viewpoint, prejudices) can be heavily challenged. Consequently, problems between such choir directors and trans* singers are rather common.

${ }^{14}$ The key of the aria was chosen due to its suitability to the participant's voice development in early 2015. 'Where'er you walk' by G.F. Handel is usually performed either by tenors in B flat ( b ) or by altos (or, more rarely, by baritones) in $\mathrm{G}$.
} 


\section{Additional Input}

During his concluding lesson, after we had completed our session, $A Z$, spontaneously, started demonstrating his ability to perform in his old manner of singing. His performance was comparable to his pre-transitional one, safe the volume and certain aspects of his previous quality, such as his former stronger singer's formant or 'ring'. Although his voice was capable of performing with a chamber orchestra, it would have been less able to cope with a bigger orchestra. In more detail, the singer's volume and timbre in March 2015 had a less penetrative quality than the one possessed by his previous singing persona. One more comparable aspect was, however, that, in order to achieve this voice quality, $A Z$ used a "head" rather than a typical falsetto type of placement and projection. Perhaps unsurprisingly, he also used his previous mode of phrasing with a rather wide type of vibrato. However, his singing was never unsafe and, as such, I did not disrupt his demonstration of continuing singing ability. Despite the lesser volume in comparison to his pre-transitional one, the voice was strong in this register and clearly possessed a singer's formant. On the same day, the singer's speaking voice, as demonstrated in the first recording (speech), was also properly "placed", full of harmonics, and projecting to an extent that our conversation was later overheard by passers-by. This is a rare quality for trans* male individuals; even those with a professional singing background.

\section{Acoustic Analysis by Aglaia Foteinou, Ph.D.}

The singer's formant cluster for operatic singers was firstly introduced by Bartholomew (1934). It consists of an additional peak of frequencies between 2500 and $4000 \mathrm{~Hz}$, centred at about $3200 \mathrm{~Hz}$ (Sundberg 2001) which allow the singers to be heard over the accompanying orchestra (Howard 2009). This can be achieved by trained classical singers (particularly basses, baritones and tenors) by "acoustically mismatching the aperture of the larynx tube, also referred to as the epilaryngeal tube, with the pharynx. This can be achieved by narrowing this aperture" (Lindblom and Sundberg, in Rossing 2015).

For the current study, the behavior of the formants of a particular excerpt of music is studied in the time and frequency domains. This was from bars 4-16 of the song "Where'er you Walk" by Handel, as shown in Figure 1. On March 2 2015, AZ performed accompanied by an orchestral backing track on a CD player. 

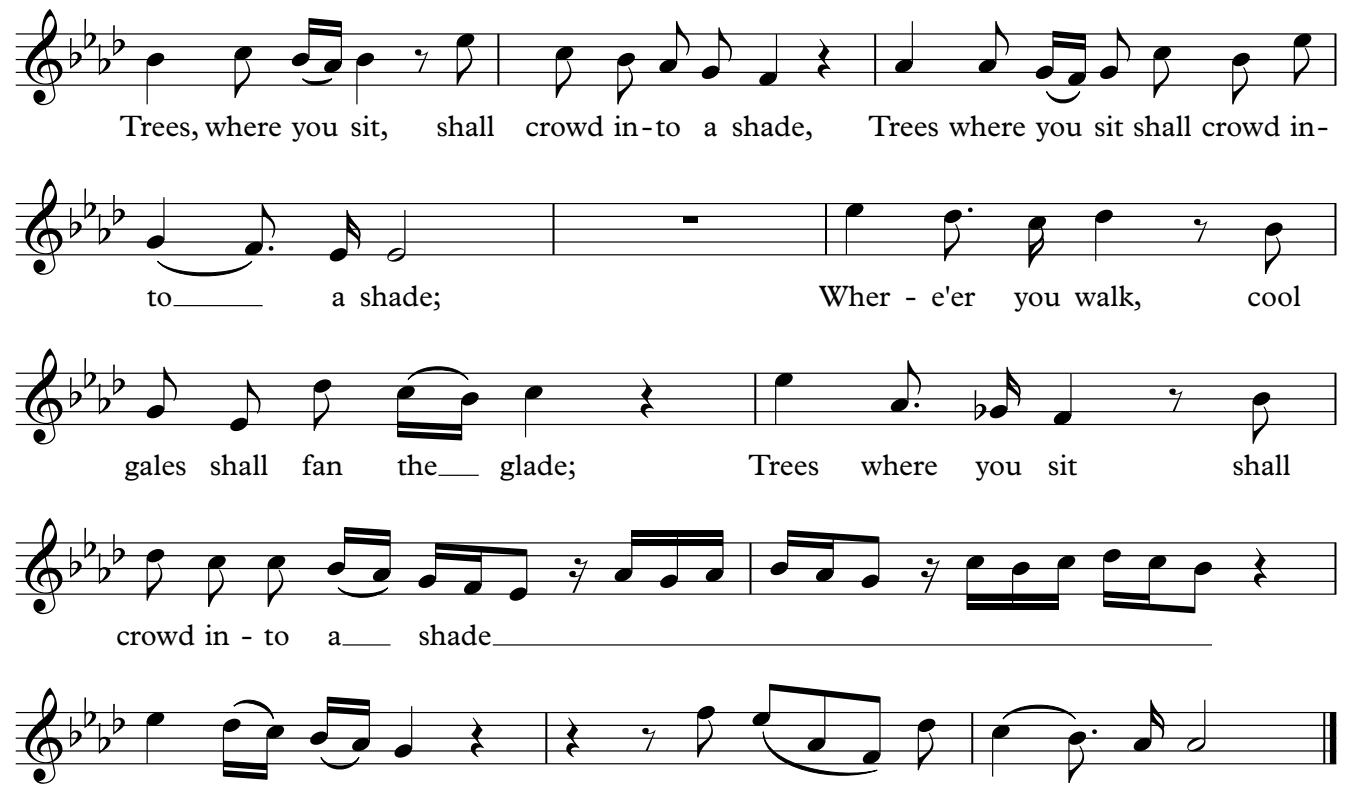

Trees, where you

shall crowd

in - to

a shade

Figure 1 (Bars 4-16): The excerpt from the aria "Where'er you Walk" by G.F. Handel which was used for the analysis in the current study.

The spectrum analysis was performed in Audacity Audio Editor, by using a Hamming Window and the FFT size of 1024 samples. The graphs are represented using a logarithmic scale for the frequency axis. Figure 2 shows the long-termaverage spectrum. It is necessary to point out that during these recordings the playback of the orchestra was also recorded in the background while the participant was performing, and the spectrum analysis contains the sound of this music. However, the maximum SPL of this background music is below $-36 \mathrm{~dB}$. Thus, the peaks above this threshold represent the SPL levels of frequencies performed by the singer.

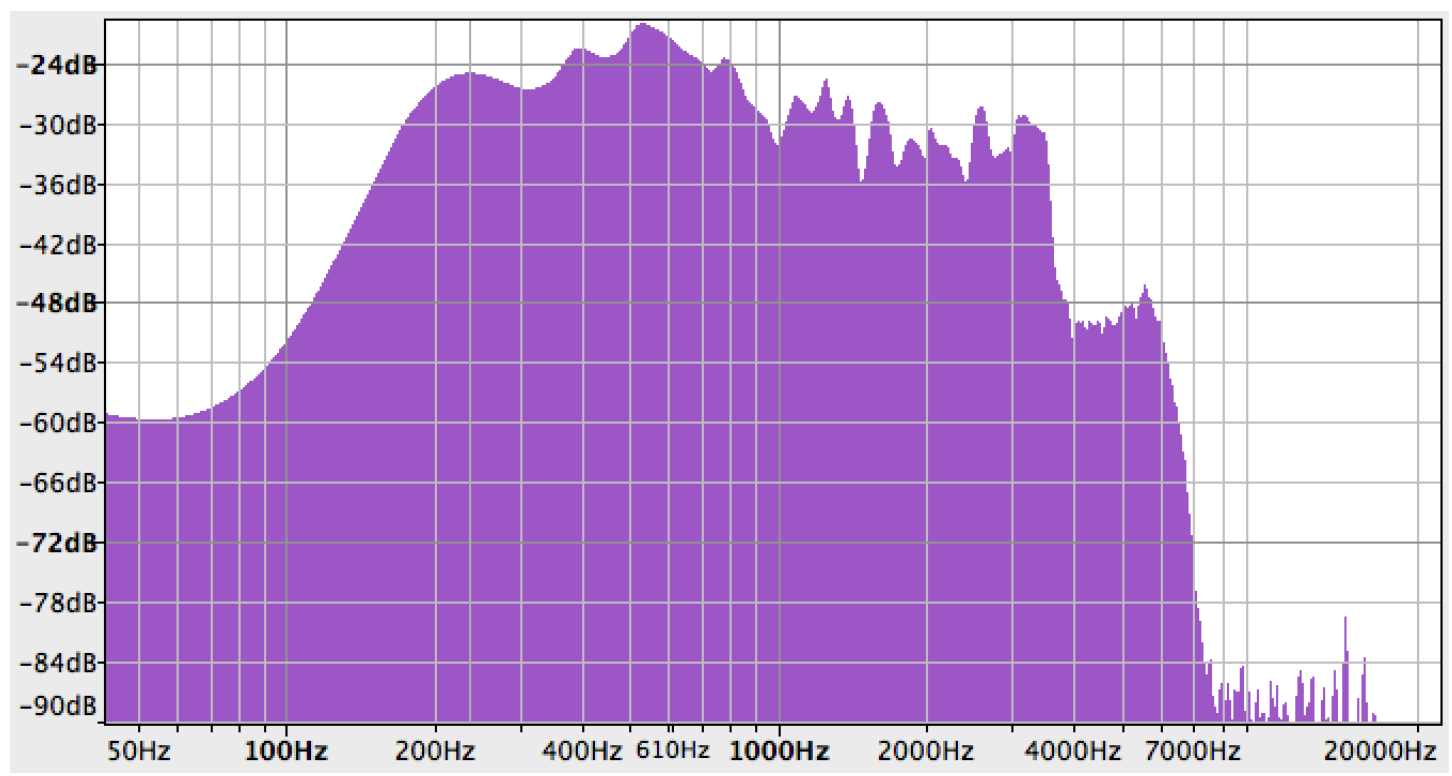

Figure 2 Long-term-average spectrum analysis of the excerpt (Bars 4-16). 
From the spectrum envelope presented here, a peak between $2000 \mathrm{~Hz}-4000 \mathrm{~Hz}$ is obvious. As has been proved in previous studies (Sundberg 2001), this peak is well above the levels of the corresponding frequencies performed by untrained voices. From a spectrogram presentation (Figure 3), the same conclusion can also be confirmed for all the syllables and notes across the sung excerpt.

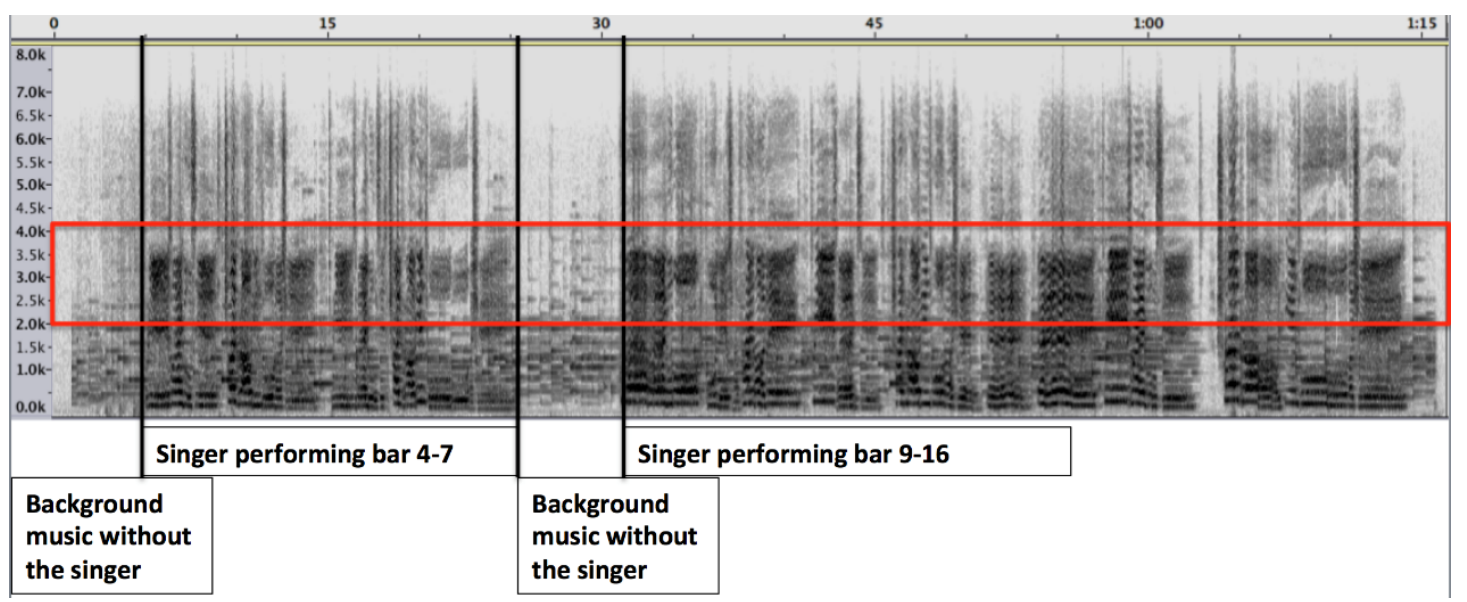

Figure 3 Spectrogram of the excerpt (Bars 4-16).

A more detail investigation was carried out focusing on the spectrum analysis of each note, starting with the first note, which was originally $B$ b (Figure 4).

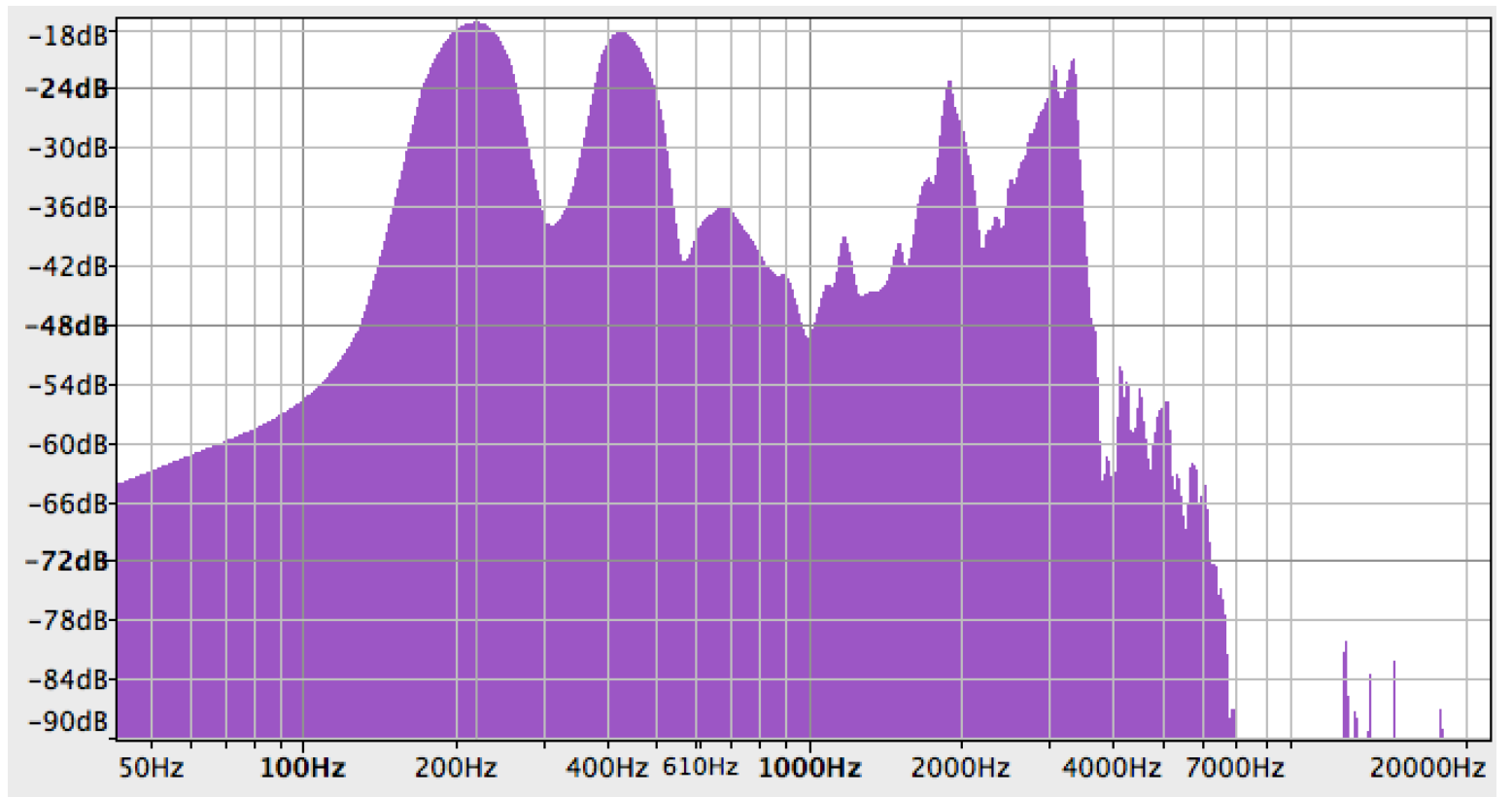

Figure $4 \mathrm{~A}$ spectrum analysis of the first note $\mathrm{A}=221 \mathrm{~Hz}$ (being original $\mathrm{B} b$ on the score) of this excerpt. The first three peaks represent the fundamental and the overtones.

From this graph, the spectrum frequency of this note can be observed as the first peak of this spectrum but the fundamental frequency is approximately $221 \mathrm{~Hz}$, followed by the peaks of the first two harmonics at $426 \mathrm{~Hz}$ and $673 \mathrm{~Hz}$. This means that the first note was not right in terms of tuning and it was performed a semi-tone down ( $\mathrm{B}$ b should be about $233 \mathrm{~Hz}$ ). Additional peaks with significant amplitude can 
be clearly observed at the frequencies of $1884 \mathrm{~Hz}, 2849 \mathrm{~Hz}$ and $3411 \mathrm{~Hz}$. In order to be more precise, the analysis of this specific note was continued by using the voice analysis program Praat, which allows formants (the acoustic resonances of the vocal tract) to be measured in detail. In Figure 5, the pitch of this note has been highlighted with a blue line (at approximately $224.7 \mathrm{~Hz}$ as an average), while the first four formants are indicated with parallel red lines, starting at $504 \mathrm{~Hz}$ for the 1st formant, $1939 \mathrm{~Hz}$ for the 2nd formant, $2849 \mathrm{~Hz}$ for the 3rd formant and $3411 \mathrm{~Hz}$ for the $4 \mathrm{th}$ formant.

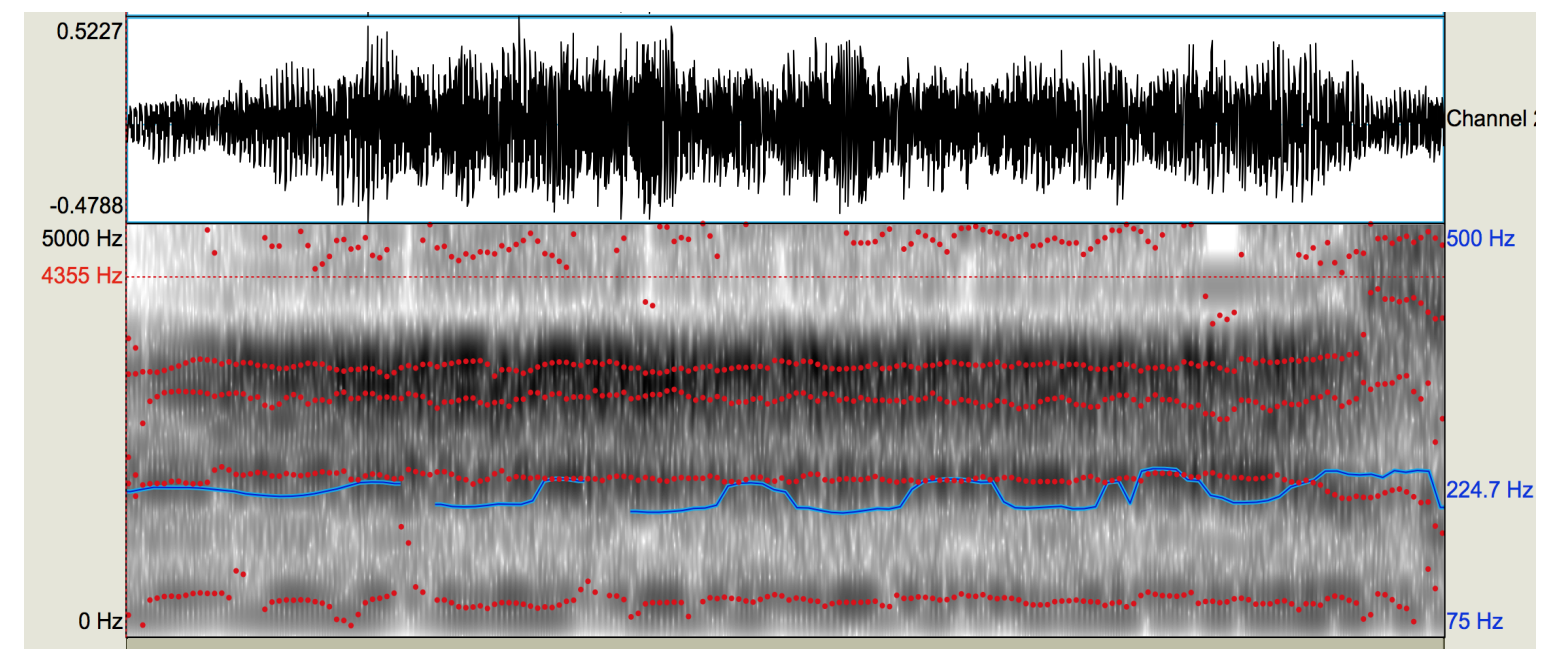

Figure 5 Analysis of the first note (A3) of this excerpt in Praat.

The analysis is carried out for the rest of the vowels of this excerpt, and the existence of the "singer's formant" at this participant's performance is confirmed, by the use of this particular technique of manipulating the vocal tract space and particularly the 2nd, 3rd, 4th formants. Overall, while just few of the notes have been performed a semi-tone down from where they appear on the score, the singer's formants can be observed at each of these notes. It is worth mentioning, however, that the central frequency and bandwidth of these formants vary depending on the vowels being sung at the time.

\section{Discussion}

Until March 2015, and despite some complications associated with distance and mode of contact, $A Z$ retained his singing ability with a clear demonstration of a singer's formant from the beginning and up to that stage of his journey to full-time masculinity. In March 2016, he further demonstrated his continuing singing ability during an online meeting. Based on that, I anticipated that his vocal development would have allowed $A Z$ to return to active auditioning and semi-professional singing posts within that academic year. This, however, relied on the past participant's continuing with his specialized vocal exercising regime. Based on current research and practice, he would have also benefited from continuing on a voice-friendlier form of testosterone administration, such as gel. However, the type of compounding testosterone gel the singer could afford until the end of his participation did not result in the best absorption rates. Even though the issue could have been remedied easily by his switching to an original gel form of testosterone administration, financial costs 
made this impossible. Furthermore, personal concerns about the medication's possible 'transfer' made him switch to a bi-monthly injectable form in June 2015, i.e. Testosterone Cypionate $200 \mathrm{mg} / \mathrm{mL}$. Despite the concerns, transfer issues associated with testosterone gels, such as Tostran $2 \%$, are alleviated by following certain precautions. These include hand-washing, covering "the application site with loose clothing... [and showering or bathing] before any situation involving close skin to skin contact with someone else" (MHRA 2015). Although careful planning is required, these reasonable adjustments are feasible when there is good communication between partners and other interested parties.

Original as opposed to compounded testosterone in gel forms may continue to prove prohibitively expensive to those less affluent. In such cases, trans* men are frequently left with no option but to replace their medication with weekly or bi-monthly injections of, for instance, Cypionate 100 or 200mg. Even in milder potencies, injectable testosterone is more aggressive than that obtained through a gel solution, such as Androgel or Tostran.

Although AZ's testosterone administration had already reached full potency on a gel-based regime, his absorption levels were not comparable to the ones obtained through injectable forms. Absorption rates are highly reliant on a person's "morphological structures", such as receptors (CNS Clinic 2007). Based on current knowledge about absorption rates and vocal changes, the relationship between different forms of testosterone administration and singing ability for trans* men is the following: changing the hormonal regime has the potential to destabilize or even impede singing ability by creating a condition similar to voice "break" for a period of time.

Assuming that an individual trans* man has a healthy disposition, he should be the one primarily choosing his hormonal regime, based on careful consideration of personal criteria. Nevertheless, participants, such as AZ, are rarely allowed to make such an independent choice. Factors beyond a person's control, such as expensive and frequently ineffective forms of compounded testosterone solutions as well as unpredictable circumstances, tend to play a significant role in the decisionmaking process. No matter the amount of careful planning, sometimes neither personal circumstances nor financial complications can be avoided. These tend to influence the health treatment decision process, even when individuals have worked and contributed to their insurance for a considerable number of years.

\section{Political Changes and their Effect}

Even with the presence of the Patient Protection and Affordable Care Act (PPACA $2010)^{15}$, there was no US national health system which was truly comparable to the British NHS or other European national health care systems, in general or in terms of gender transition. Due to the political changes brought by the November 8, 2016 election in the USA, the form of the Affordable Care Act which remained valid until July 2017 was anticipated to be challenged. In preparation, long before the inauguration of the new president in January 2017, "individual state regulators...[had] taken steps to ensure that transgender people [would] have access to care related to gender transition" (Baker 2017, 3). ${ }^{16}$ The new

\footnotetext{
${ }^{15}$ For a detailed history behind the introduction of the PPACA (Affordable Care Act), see Baker, 2017.

${ }^{16}$ As mentioned by Baker,

Since 2012, a total of 18 states (including California) and the District of Columbia have interpreted their own laws as prohibiting private plans from discriminating against transgender
} 
administration confirmed its wishes to replace the Affordable Care Act with the American Health Care Act (AHCA) in 2017. However, the new Act, which was passed by the House on May 4 and was to be considered by the Senate before the August recess, was also challenged (see Baker 2017b). This is because, as stated by Palosky and Singh, the American Health Care Act was anticipated to "reduce the federal government's role and resources in providing health insurance coverage particularly for people with low or moderate incomes - while expanding authority and financial responsibility of the states" (2017, online). On July 28, 2017, Arizona Senator "McCain... joined fellow Republicans Susan Collins of Maine and Lisa Murkowski of Alaska in voting down the so-called "skinny repeal" bill 51-49" (Jacobs et al. 2017, online).

\section{Interim Conclusion}

This case study has demonstrated that AZ, a 52-year-old trans* male participant with a lengthy professional singing career, was able to retain his uninterrupted vocal ability throughout his gender transition (2013-2014) as well as a singer's formant; an aspect which, until 2012 (see Appendix 2), had remained unproven for trans* male voices. The singer's capability was achieved by adopting a lower start/more gradual increase method of testosterone administration than the one followed by the low start/gradual increase group of the Trans* Male Singing Program. The lower and more gradual testosterone dosage was accompanied by the same vocal exercises used by all participants in the Program (low start/gradual increase vs. abrupt regime). This set of exercises was slightly adapted to support AZ's individual needs, i.e. for him to retain a singing and performing ability as part of his transition. Since the completion of his participation, the adapted set of exercises have become an integral part of the main Singing Trans* Male Voice Program and are currently used by all participants, in spite of the current issues with the Program.

AZ's participation has produced positive and trusted results (see Results and Acoustic Analysis). However, his progress has also been held back by economic issues, among them the concurrent funding ones associated with the Singing Trans* Male Program. Both have prevented the singer from continuing with his regular voice lessons post-transition and, thus, from realizing his full potential. As such, although $A Z$ is currently singing baritone in a semi-professional choir, the long-term results of his participation remain inconclusive. The case study would need to be replicated by another participant or participants with the same background and aims. The new participants would need to be fully supported (i.e. funded) throughout the physical and vocal changes associated with trans* male transition. Ensuring the presence of stable and generalizable living conditions for all participants would be a conditio sine qua non for producing replicable quantitative and/or qualitative research results.

\section{Afterthoughts}

Gender affirmation or transition is already a stressful period for anyone involved, directly or indirectly. The person is frequently overwhelmed by regulations. Under such circumstances, the role of relevant health organisations and committees, such as the Center for American Progress or the Women and Equalities Committee (UK 2016) can prove truly important, because they can remedy such injustices. As part of this process, it can place pharmaceutical companies under greater control instead of 
allowing them carte blanche over individuals' lives, health and voices. Until such social injustices are addressed more adequately, trans* singing talents will continue to be undermined and their increasingly positive vocal results will be treated as purely individual and, thus, less generalizable and less valued. ${ }^{17}$

\section{References}

Baker, Kellan E. 2017a. "Perspective: The Future of Transgender Coverage." The New England Journal of Medicine 376, 1801-1804. In www.NEJM.org Accessed: April 132017.

2017b. "Trans People in the Health Reform Fight: What's at Stake." The

Body: The Complete HIVIAIDS Resource. In

http://www.thebody.com/content/80046/trans-people-in-the-health-reform-fight-

whats-at-s.html?ap=1100 Accessed: June 152017.

Bartholomew W.T. 1934. "A physical definition of 'good voice-quality' in the male voice", Journal of the Acoustical Society of America 6: 25-33.

Biederman, Joseph. 2005. "Attention-Deficit Hyperactivity Disorder: A Selective Overview." Biological Psychiatry 57: 1215-1220. In

http://www.sciencedirect.com/science/article/pii/S000632230401100X. Accessed: February 52016.

Biederman, Joseph, and Stephen V. Faraone. 2005. Seminar: "Attention-Deficit Hyperactivity Disorder." Lancet 366: 237-248. In

\footnotetext{
${ }^{17}$ My sincere thanks to $A Z$, the participant of this case study, whose sheer vocal gift and dedication became the inspiration behind this ongoing study. Also, my earnest appreciation to all previous contributors of the Singing Trans* Male (previously "FTM") Voice program. Without your collective talents, trust, persistence and valued input, both the study and the Singing Trans* Male program would not have progressed and, thus, helped numerous individuals worldwide. Likewise, my heartfelt thanks to Dr. Aglaia Foteinou (University of Wolverhampton, Wolverhampton, UK) for her valuable scientific cooperation and contribution to the case study and this article. Finally, my profound gratitude to all close friends and esteemed academic colleagues and mentors whose continuing support and encouragement have allowed the study and the Program to overcome the boundaries of independent research and practice.
}

The article is dedicated to the memory of Niki (2015). 
http://www.sciencedirect.com/science/article/pii/S0140673605669152. Accessed: February 52016.

Brown, lan, Brown, Lindsey, and Douwe Korff. 2010. "Using patient data for research without consent." Law, Innovation and Technology, 2, 219-258. In Brown, Ian, Brown, Lindsey, and Douwe Korff. 2011. "The Limits of Anonymisation in NHS data systems", British Medical Journal (BMJ) 342: 238. In

http://www.bmj.com/rapid-response/2011/11/03/limits-anonymisation-nhs-datasystems. Accessed: February 52016.

Constansis, Alexandros N. 2009. "Hybrid Vocal Personae." Ph.D. thesis. York: University of York.

2008. "The Changing Female-to-Male (FTM) Voice." Radical Musicology 3: 32 pars. In http://www.radical-musicology.org.uk/2008/Constansis.htm. Accessed: February 52016.

. 2004. "The Changing FTM Voice." Unpublished paper. In $6^{\text {th }}$ International Congress on Sex and Gender Diversity: Reflecting Genders (September 10-12). Manchester: Manchester Metropolitan University.

CNS Clinic - Jordan. 2016. "Receptors". In

http://www.humanneurophysiology.com/receptors.htm. Accessed: February 52016.

European Professional Association for Transgender Health (EPATH). 2017. "Contemporary Trans Health in Europe: Focus on Challenges and Improvements." Program Book. $2^{\text {nd }} E P A T H$ Conference. Belgrade, Serbia. In http://epath.eu/wpcontent/uploads/2016/06/Programbook_EPATH_2017TOTAL_onlineversion.pdf

Accessed: May 152017.

Feldman, Martha. 2015. The Castrato: Reflections on Natures and Kinds. Oakland, California: University of California Press.

Gates, Rachael, Arick Forrest L., and Kerrie Obert. 2013. The Owner's Manual to the Voice: A Guide for Singers and Other Professional Voice Users. Oxford and New York: Oxford University Press.

Gorton, Ryan Nick, Buth, Jamie, and Dean Spade. 2005. Medical Therapy and Health Maintenance for Transgender Men: A Guide for Health Care Providers. San Francisco: Lyon-Martin Women's Health Services.

Handel, G.F. 1743. Semele (Concert Edition [n.d.], Vocal Score, adapted from the complete edition of Ebenezer Prout). London: Novello Publishing.

Hickey, Jocelyn E. 2011. "The Voice in the Darkness: One Singer's Journey to Individuation." MMusPerf Thesis. Melbourne: University of Melbourne.

Howard, David M., and Jamie A.S. Angus. 2009. Acoustics and Psychoacoustics. 4th Edition. Oxford: Focal Press.

Howes, Patricia, Callaghan, Jean, Davis, Pamela, Kenny, Dianna, and William Thorpe. 2004. "The Relationship between Measured Vibrato Characteristics and Perception in Western Operatic Singing." Journal of Voice 18 (2): 216-229. 
Jacobs, Ben, Gambino, Lauren, and Lois Beckett (in Washington). 2017. "US Healthcare: John McCain sinks 'skinny repeal' of Obamacare health act." The Guardian. In https://www.theguardian.com/us-news/2017/jul/28/healthcare-bill-ussenate-votes-down-obamacare-skinny-repeal-revolt-by-john-mccain Accessed: July 282017.

Lamperti, Francesco, transl. JC Griffith. 1939. The Art of Singing. Revised Edition. New York: G. Schirmer.

Levy, Andy, Crown Anna, and Russell Reid. 2003. "Endocrine Intervention for Transsexuals." Clinical Endocrinology 59: 409-418.

Lindblom, Björn, and Johan Sundberg, "The Human Voice in Speech and Singing", 719. In Springer Handbook of Acoustics, edited by Thomas Rossing, 2015. $2^{\text {nd }}$ Edition. Stanford, CA: Springer.

Medicines and Healthcare Products Regulatory Agency [MHRA]. 2015. "Tostran 2\% Testosterone: Information for the user." In

http://www.mhra.gov.uk/home/groups/spcpil/documents/spcpil/con1453441063628.p df. Accessed: February 52016.

Moriarty, B.M., 2015, 'Crossing Over: Examining the Challenges of a Classically Trained Female Performing Music Theatre Repertoire'. DMA Thesis. The University of North Carolina at Greensboro.

Norman, Robert E., ed. 2008. Diagnosis of Aging Skin Diseases. Florida: Springer.

Palosky, Craig, and Rakesh Singh. 2017. "What Challenges Could State Insurance Markets Face Under the House's American Health Care Act?". The Henry J. Kaiser Family Foundation. In http://www.kff.org/health-reform/press-release/whatchallenges-could-state-insurance-markets-face-under-the-houses-american-healthcare-act/ Accessed: June 152017.

Praat (software), in http://www.fon.hum.uva.nl/praat/. Accessed: June 302016.

Price, Linda, Richardson, John T.E., and Anne Jelfs. 2007. "Face-to-face versus online tutoring support in distance education." Studies in Higher Education 32 (1): 120.

Roberts, Walter, Milich, Richard and Russell A. Barkley. 2014. "Primary Symptoms, Diagnostic Criteria, Subtyping, and prevalence of ADHD”, 51-80. In Attention-Deficit Hyperactivity Disorder: A Handbook for Diagnosis and Treatment, edited by Russell A. Barkley. $4^{\text {th }}$ Edition. New York: The Guildford Press.

Rossi, Luca, Musolesi, Mirco and Andrea Torsello. 2015. "On the k-Anonymization of Time-Varying and Multi-Layer Social Graphs." AAAI Publications/Ninth International AAAl Conference on Web and Social Media. ICWSM Conference Full Papers. In 
http://www.ucl.ac.uk/ ucfamus/papers/icwsm15_kanonymization.pdf. Accessed: February 52016.

Sataloff, Robert Thayer, Divi, Venu, Heman-Achah, Yolanda D., and Mary J. Hawkshaw. 2007. "Medical History in Voice Professionals." Otolaryngology Clinics of North America 40 (5): 931-951.

Sataloff, Robert Thayer, and Sue Ellen Linville. 2006. "The Effects of Age on the Voice", 17-32. In Vocal Health and Pedagogy: Advanced Assessment and Treatment, edited by Robert Thayer Sataloff, $2^{\text {nd }}$ Edition. San Diego and Oxford: Plural Publishing.

Shepherdson, Charles. 2006. "Selection from 'The Role of Gender and the Imperative of Sex"', 94-102. In The Transgender Studies Reader, edited by Susan Stryker and Stephen Whittle. New York and London: Routledge.

Snider, Jeffrey. 2012. "In Search of the Soprano Sfogato." Journal of Singing 68 (3): 329-334.

Sokol, Daniel K. 2013. "'First do not harm' revisited." British Medical Journal (BMJ) 347: f6426.

Stryker, Susan. 2008. Transgender History. Berkeley, CA: Seal Press.

. 2006. "(De)Subjugated Knowledge: An Introduction to Transgender Studies", 1-17. In The Transgender Studies Reader, edited by Susan Stryker and Stephen Whittle. New York and London: Routledge.

Sundberg, Johan. 2001. "Level and center frequency of the singer's formant." Journal of Voice 15: 176-186.

1994. "Acoustic and Psychoacoustic Aspects of Vocal Vibrato." STLQPSR, KTH Computer Science and Communication 35 (2-3): 45-68.

Swanson, Frederick.1981. "The Young Male with a Changing Voice." NATS Bulletin 38 (1): 32-34.

Talley, Nicholas Joseph, and Simon O' Connor. 2014. Examination Medicine: A Guide to Physician Training. $7^{\text {th }}$ Edition. Chatswood, NSW: Churchill Livingstone.

Timimi, Sami, and Jonathan Leo. 2009. Rethinking ADHD: From Brain to Culture. London and New York: Palgrave MacMillan.

Tommasini, Anthony. 2007. "An Appraisal. That Voice: Warm, Urgent, Italian, Singular." New York Times. In

http://www.nytimes.com/2007/09/07/arts/07/uci.html?pagewanted=print\&_r=1.

Accessed: February 52016.

Transgender Europe (TGEU). 2015. "Malta Adopts Ground-Breaking Trans and Intersex Law - TGEU Press Release." In

http://tgeu.org/malta-adopts-ground-breaking-trans-intersex-law/ Accessed: May 15 2017. 
U.S. Government Publishing Office. 2010. "PUBLIC LAW 111 - 152 - HEALTH CARE AND EDUCATION RECONCILIATION ACT OF 2010." In https://www.gpo.gov/fdsys/pkg/PLAW-111publ152/content-detail.html Accessed: January 52017.

Verschoor, AM, and J. Poortinga. 1988. "Psychosocial Differences between Dutch Male and Female Transsexuals." Archive of Sexual Behaviour 17 (2): 173-178.

Vest, Jason, 2014, 'The Weightier Matters: Low Larynx Positioning and Adolphe Nourrit.' Journal of Singing 71 (1): 27-34.

Whittle, Stephen. 2006. "Foreword", xi-xvi. In The Transgender Studies Reader, edited by Susan Stryker and Stephen Whittle. New York and London: Routledge.

Wille, Reinhard, and Klaus M. Beier. 1989. "Castration in Germany." Annals of Sex Research 2: 103-133.

Women and Equalities Committee. 2016. "Transgender Equality: First Report of Session 2015-16". The House of Commons. London: The Stationery Office. In

http://www.publications.parliament.uk/pa/cm201516/cmselect/cmwomeq/390/390.pdf Accessed: February 52016. 


\section{Appendices}

1. The Singing Trans* Male ("FTM") Voice Program: Exercise Example

Voice
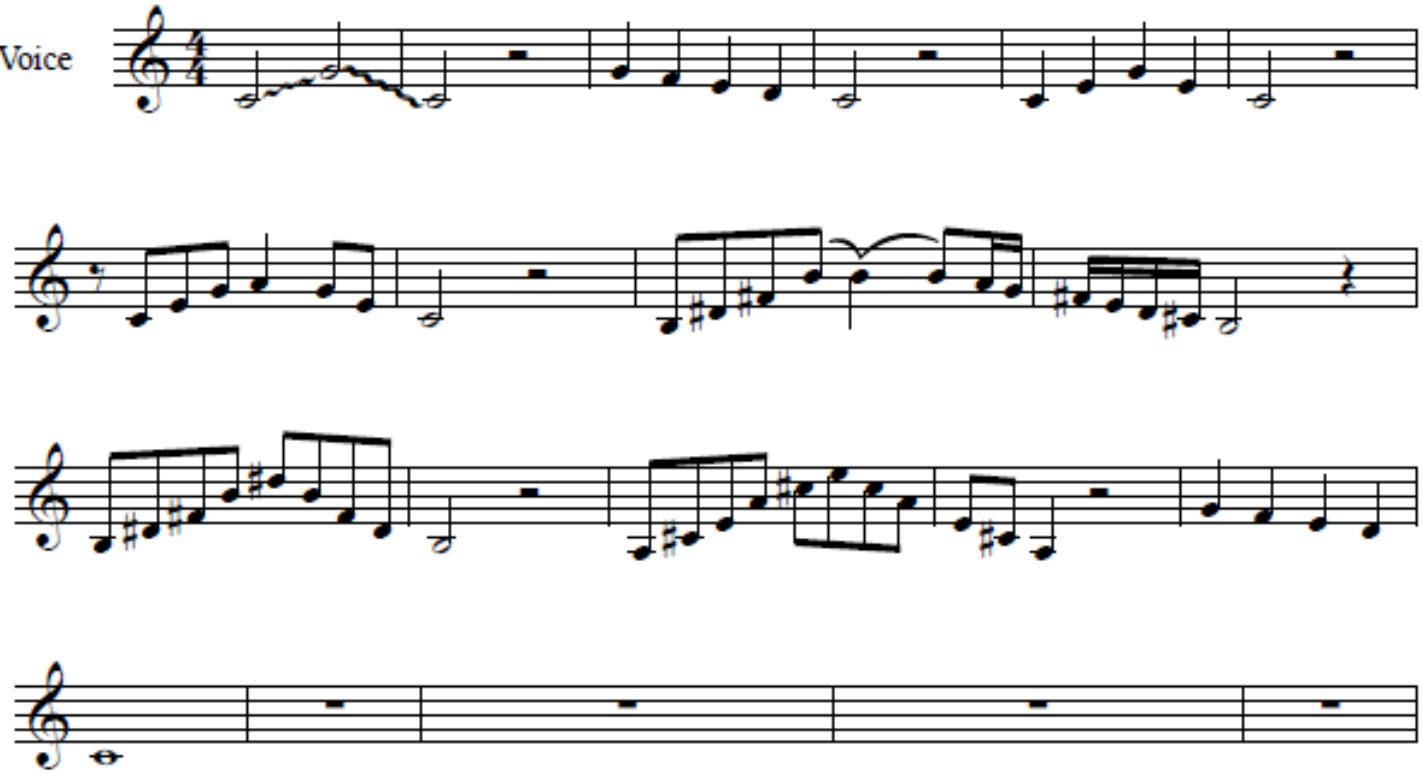

Although these exercises (only a sample) can be found almost intact in old bel canto methods of singing, for the purposes of this Program, they are approached differently. More modern techniques, such as singing on fricatives, the use of lip trills and glissandi or "sirens" etc., enhance the traditional bel canto phrasing and breathing approach. As such, the solid breathing and appoggio technique of bel canto is only enhanced and adapted for the trans* male singer; never compromised.

The Program exercises should be performed with direct supervision by a qualified and experienced singing practitioner. 
2. Case Study (unpublished): "The Presence of a Singer's Formant in the Singing Female-to-Male (FTM) Voice." ${ }^{\text {"18 }}$

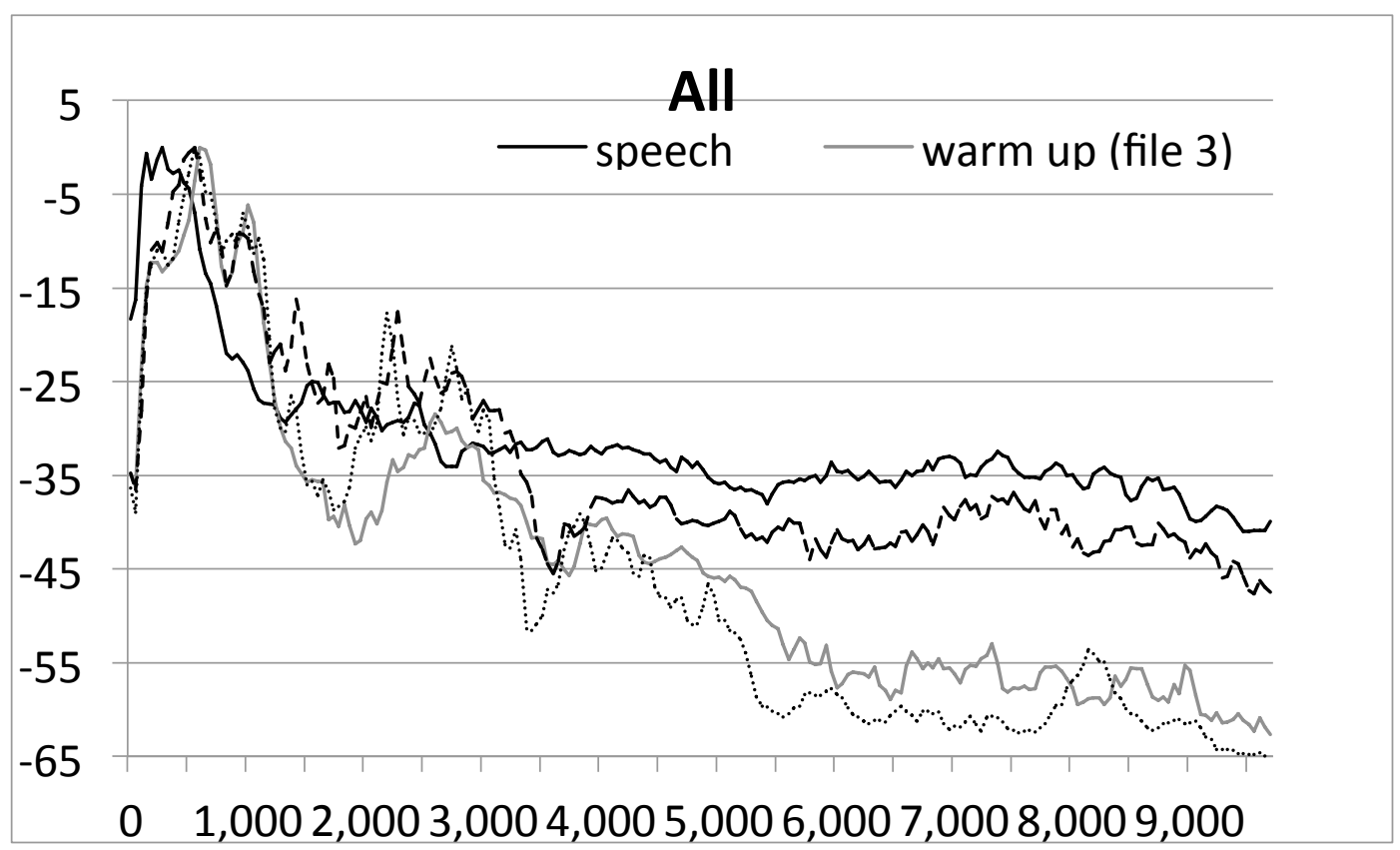

\footnotetext{
${ }^{18}$ Recordings and acoustic analyses (LTAS) were conducted by Professor David M. Howard (July and October 2012). Participant: Alexandros N. Constansis.
}

The graph was first included in Constansis 2013. 